\title{
Estratégias de coping para cônjuges de idosos com diagnóstico neuropsiquiátrico
}

\author{
Coping strategies for conjugality of elderly \\ partners with neuropsychiatric diagnosis
}

\section{Giovana Cristina Comelli ${ }^{1}$ (D) Sabrina Martins Barroso ${ }^{2}$ (D)}

\author{
'Universidade Federal do Triângulo Mineiro (Uberaba). Minas Gerais, Brasil. giovana.comelli@hotmail.com \\ ${ }^{2}$ Autora para correspondência. Universidade Federal do Triângulo Mineiro (Uberaba). Minas Gerais, Brasil. smb.uftm@gmail.com
}

RESUMO | INTRODUÇÃO: A relação conjugal satisfatória é tida como um importante suporte de bem-estar social, principalmente frente a situações estressoras. Os diagnósticos neuropsiquiátricos podem ser um importante estressor, que pode abalar as relações conjugais de idosos. OBJETIVOS: Este estudo de caso teve por objetivo compreender as estratégias de coping para conjugalidade utilizadas por dois cônjuges de idosos com o diagnóstico neuropsiquiátrico. MÉTODOS: Os participantes, um homem e uma mulher, eram casados com participantes do Projeto de Extensão “Movimente”, desenvolvido na Universidade Federal do Triângulo Mineiro, em Uberaba, Minas Gerais. Os idosos foram convidados e participaram de uma entrevista semiestruturada, com questões sobre o casamento antes e após o diagnóstico, suas estratégias para lidar com a conjugalidade e o diagnóstico do(a) parceiro(a). As entrevistas foram realizadas individualmente, em local separado de seus(suas) parceiros(as). As entrevistas foram transcritas e analisadas por meio de análise de conteúdo temática e interpretados com base na Psicologia da Saúde. RESULTADOS: Foram identificadas três categorias: 1) Conjugalidade e mudanças trazidas pela doença 2) Coping focalizado na emoção 3) Coping focalizado no problema. As principais estratégias de coping utilizadas pelos idosos foram comprometimento, admiração e crença religiosa. DISCUSSÃo E CONCLUSÃO: As estratégias se mostraram importantes para manter a boa conjugalidade, mesmo sendo observada mudança de foco do casamento para a função de cuidador, diante de diagnóstico neuropsiquiátrico.

PALAVRAS-CHAVE: Coping. Casamento. Envelhecimento. Demência.

\begin{abstract}
INTRODUCTION: The satisfactory marital relationshipisseen as animportantsupportfor socialwell-being, especially in the face of stressful situations. Neuropsychiatric diagnoses can be being, especially in tstressful situations. Neuropsychiatric diagnoses can be an important stressor, which can affect the marital relationships of the elderly. OBJECTIVES: This case study aimed to understand the coping strategies for conjugality used by two elderly spouses with a neuropsychiatric diagnosis. METHODS: Participants, a man and a woman, were married to participants in the "Movimente" Extension Project, developed at the Federal University of Triângulo Mineiro, in Uberaba, Minas Gerais. The elderly were invited and participated in a semi-structured interview, with questions about marriage before and after the diagnosis, their strategies for dealing with conjugality and the diagnosis of the partner. The interviews were carried out individually, in a place separate from their partner. The interviews were transcribed and analyzed through thematic content analysis and interpreted based on Health Psychology. RESULTS: Three categories were identified: 1) Conjugality and changes brought about by the disease 2) Coping focused on emotion 3) Coping focused on the problem. The main coping strategies used by the elderly were commitment, admiration and religious belief. DISCUSSION AND CONCLUSION: The strategies proved to be important to maintain good conjugality, even though there was a change in focus from marriage to the role of caregiver, in the face of neuropsychiatric diagnosis.
\end{abstract}

KEYWORDS: Coping. Marriage. Aging. Dementia. 


\section{Introdução}

$\mathrm{Na}$ contemporaneidade, o casamento ainda pode ser visto como um caminho para felicidade. Como fonte de laços que não podem ser rompidos e de um compromisso que será assumido "para sempre". Para que uma relação de longo prazo se mantenha, é necessário que os casais encontrem formas para superar dificuldades e momentos de crise, e as formas de enfrentamento (coping) utilizadas irão depender das habilidades que cada casal possui para lidar com as situações. Casais que estão envolvidos em casamentos mais satisfatórios e que possuem um bom grau de intimidade experienciam conforto e bem-estar, o que pode levar a reforçar as habilidades de enfrentamento de determinadas situações (Silva et al., 2017).

O conceito de conjugalidade é embasado em três fatores: a satisfação, o ajustamento e a qualidade conjugal. A satisfação e o ajustamento são interligados, pois os casais mais satisfeitos são aqueles que, em contato com obstáculos do meio, se ajustam a eles. Enquanto a qualidade conjugal seria o resultado da interação que o casal tem e como eles a vivenciam (Garcia, 2018). Dessa forma, entende-se que, ao haver um comprometimento de dois indivíduos em uma união estável de longa duração, os dois precisam desenvolver um modelo de funcionamento conjugal.

De acordo com Norgren et al. (2004), hoje sabe-se da complexidade da satisfação conjugal, que envolve aspectos relacionados a personalidade, valores, necessidades, sexo, presença de filhos, aspectos sociais e econômicos. Além disso, muitos casais permanecem juntos apesar de não possuírem um bom relacionamento. Quando as relações são satisfatórias e duradouras, permitem que a conjugalidade sirva de refúgio para situações estressoras, se transformando em fonte de crescimento pessoal e aprendizagem. Algo relevante frente à longevidade cada vez maior da população.

No que concerne às crises, transições da vida e estressores externos, o adoecimento de um dos cônjuges pode representar um importante ponto. $O$ surgimento de um quadro neuropsiquiátrico, mais frequente em pessoas idosas, pode ser um estressor que surge em casamentos duradouros. Segundo a Alzheimer's Disease International (2016), aproximadamente 46,8 milhões de pessoas tiveram o diagnóstico de demência, podendo este número alcançar 131,5 milhões até 2050. As demências possuem características crônicas e progressivas, prejudicando diversas funções cerebrais, principalmente a função cognitiva, que costuma também estar associada à redução do controle emocional, do comportamento social e da motivação.

Segundo a American Psychiatric Association (2014), as demências passaram a ser designadas como Transtorno Neurocognitivo Maior, sendo que a Doença de Alzheimer merece destaque entre tais transtornos (Mattos \& Kovács, 2020). Estudos epidemiológicos têm demonstrado que o diagnóstico de Alzheimer dobra a cada cinco anos em pessoas com idades entre 65 e 85 anos, o que tem preocupado a saúde pública (Viero \& Santos, 2019). O Alzheimer é um tipo de demência que se manifesta a partir da perda gradativa da função cognitiva, atingindo primeiramente a função intelectual, posteriormente o humor, o comportamento, causando desorientação, perda de memória, imobilidade e morte do indivíduo. Ao ser acometido por essa doença a pessoa perde a capacidade de autonomia e independência, necessitando de cuidados nas atividades diárias, podendo precisar de um cuidador (Silva et al., 2015).

É relevante ressaltar a importância da qualidade da relação conjugal duradoura no contexto das demências, visto que os cônjuges são os principais cuidadores e o nível de intimidade do casal antes do diagnóstico é um aspecto que pode impactar os efeitos negativos na prestação de cuidados pelo cônjuge. Portanto, se o relacionamento conjugal possuía uma má qualidade antes do diagnóstico da doença, há uma maior associação de depressão, baixa qualidade de vida e menor satisfação na realização dos cuidados com o parceiro (Sales \& Menezes, 2017).

Souza et al. (2016) demonstram que a relação de quem cuida de um cônjuge com Alzheimer impulsiona o próprio cuidador a remodelar sua vida para melhor se doar para o outro. Essa relação pode ser embasada pelo amor e fidelidade que construíram durante os anos de matrimônio, que faz com que o cuidador se doe, se dedique e faça abdicações em nome de seu cônjuge adoecido. Além disso, essa relação também pode ser movimentada pelos laços familiares, quando estes foram criados de forma sólida durante a trajetória de vida do casal, permeado de cuidados mútuos e cumplicidade. 
Mussumeci e Ponciano (2018) pontuam que os cônjuges também podem vivenciar situações de estresse que são capazes de ocasionar mudanças e interferir tanto de forma positiva quanto negativa no casal. Portanto, o casal estabelece estratégias próprias para lidarem com as frustrações e dificuldades que aparecem, e passam a buscar alternativas para se adaptar as mudanças. Em seu estudo sobre estratégias de coping de casais, os autores observaram consistência em relação aos dados encontrados na literatura, que trazem que os casais que se manifestam felizes e satisfeitos revelam ter melhor qualidade de vida conjugal a partir do uso de estratégias de coping positivas para lidar com o estresse.

Para Lazarus e Folkman (1991), as estratégias adotadas para o enfrentamento de uma situação estressante, denominadas de coping, são esforços cognitivos e comportamentais elaborados para o controle de necessidades específicas, servindo como resposta do indivíduo a situações adversas que podem estar sobrecarregando ou ultrapassando seus limites de recursos pessoais. O modelo de Folkman e Lazarus (1980) abrange quatro conceitos primordiais para compreensão do enfrentamento: 1 . O coping é um processo que acontece entre o indivíduo e o ambiente; 2 . Sua atribuição é a administração da situação estressora; 3. Os processos de coping presumem como a situação estressora é interpretada e cognitivamente representada para o indivíduo; e 4. Nos processos de coping há uma mobilização de esforços cognitivos e comportamentais para que o indivíduo possa administrar as demandas internas e externas que surgem na situação estressora.

Dessa forma, o coping pode se apresentar de duas maneiras, o enfrentamento tendo como função gerenciar o evento estressor, sendo assim, focalizado no problema. Ou como forma para controlar, reduzir e eliminar as respostas emocionais que surgem a partir desse estressor, sendo focalizado na emoção (Lazarus \& Folkman, 1991). Lazarus e Folkman (1991) definem que o modelo de estresse é dinâmico e interacional, e envolvem níveis de avaliação ou apreciação primária ou secundária. Na primária, o indivíduo analisa de que forma ele foi atingido pela situação estressora, auxiliando na qualidade e intensidade da sua reação emocional. Na secundária o indivíduo está em busca de soluções para enfrentar a situação estressora, esse nível contribuirá nas escolhas dos tipos de estratégias que a pessoa irá optar para enfrentar determinada situação.
Os enfrentamentos focalizados no problema são utilizados quando a situação é vista pelo indivíduo como algo reversível, que pode ser alterada, enquanto os enfrentamentos focalizados na emoção são mais utilizados se a situação é inalterável, irreversível.

As duas formas de enfrentamento podem ser utilizadas por uma mesma pessoa diante de um mesmo estressor, isso porque uma estratégia de enfrentamento focalizada no problema também pode ser uma estratégia focalizada na emoção, atuando de forma dinâmica e recíproca. Além do mais, cada pessoa utiliza determinada forma de enfretamento de acordo com sua história de vida, com as habilidades que possui e a forma como encara a situação estressora (Pinto \& Barham, 2014).

À vista disso, Sales e Menezes (2017) ressaltam a relevância de compreender os efeitos do adoecimento neuropsiquiátrico sobre o casal, dado que os principais cuidadores de idosos são os cônjuges e o surgimento de um quadro neuropsiquiátrico pode gerar deterioração na qualidade de vida e menor satisfação com o relacionamento. Isto posto, e levando em consideração a importância do relacionamento conjugal duradouro, o objetivo deste estudo é compreender as estratégias de coping para conjugalidade utilizadas por dois cônjuges de idosos com diagnóstico neuropsiquiátrico.

\section{Método}

\section{Tipo de estudo}

Esta pesquisa realizou-se na forma de um estudo de caso, desenvolvido com duas pessoas, sendo uma mulher e um homem idosos, que mantinham casamentos de longa duração e que o cônjuge recebeu diagnóstico de transtorno neuropsiquiátrico. $\mathrm{O}$ estudo de caso consiste em uma investigação empírica que visa analisar um fenômeno contemporâneo com profundidade no contexto do mundo real. Esse tipo de estudo não é generalizável às populações ou aos universos, porém ele contribuirá para expandir e generalizar teorias. A teoria utilizada no projeto inicial do estudo de caso é aprimorada com os resultados de tal estudo, e servirão de base para generalizações analíticas (Yin, 2015). O projeto foi aprovado pelo Comitê de Ética em Pesquisa (CAAE: 26082719.6.0000.5154). 


\section{Participantes}

A pesquisa foi realizada com um homem e uma muIher com mais de 60 anos de idade, são casados com parceiros que possuíam diagnóstico de Alzheimer, previamente confirmado por médicos da instituição e constante de inscrição. Os participantes residem em Uberaba, Minas Gerais, uma cidade de porte médio da região do Triângulo Mineiro e foram localizados por meio do projeto de extensão universitária "Movimente", desenvolvido pelo curso de Educação Física da Universidade Federal do Triângulo Mineiro.

Os dois levavam e buscavam seus parceiros no projeto, o qual tem o objetivo de proporcionar atividades físicas para idosos com o diagnóstico de Alzheimer, visando à melhora na condição cognitiva e motora do indivíduo. Os participantes do estudo que foram identificados apenas por uma letra ( $F$ ou $A$ ) na apresentação das falas, para resguardar suas identidades e suas características sociodemográficas quando realizadas as entrevistas eram:

F., sexo masculino, 82 anos de idade quando entrevistado, casado há 54 anos. Possuía ensino superior completo, era aposentado, antes trabalhava como professor e tinha três filhos. Tinha renda média de 4 salários-mínimos. Vivia com a esposa em casa própria. A esposa havia recebido diagnóstico de Alzheimer 5 anos antes do momento da entrevista.

A., sexo feminino, tinha 70 anos quando entrevistada, era casada há 50 anos, tinha $1^{\circ}$ grau completo, trabalhava com o marido na serralheria do casal até se aposentar e tinha dois filhos. Tinha renda média de 3 salários-mínimos. Vivia com o marido, a filha, o genro e a neta, na casa da filha. O marido havia recebido diagnóstico de Alzheimer 3 anos antes do momento da entrevista.

\section{Coleta de dados}

Os participantes foram contatados inicialmente por telefone, sendo explicado o propósito da pesquisa e o caráter voluntário da participação e foi feito o convite para participar da pesquisa. Após aceito o convite, os participantes assinaram o Termo de Consentimento Livre e Esclarecido. Posteriormente, foi realizada a entrevista semiestruturada, na moradia do participante, de forma individual e sem a presença do cônjuge. $O$ roteiro de entrevista abrangia o casamento antes e depois do diagnóstico, as dificuldades e emoções vividas e as estratégias adotadas para manejar o casamento e outras situações ao longo da convivência.

\section{Análise de dados}

Os dados coletados foram transcritos e analisados de acordo a metodologia de análise de conteúdo temática, apresentada por Campos e Turato (2009). Esses autores indicam que a análise de conteúdo tem como objetivo buscar o sentido das informações dos materiais coletados.

Inicialmente foi realizada a leitura flutuante das entrevistas transcritas. Posteriormente foi feita a análise dos conteúdos manifestos e latentes. Para tanto foi realizada a inferência do conteúdo, que consiste em reafirmar uma proposição a partir da relação com outras proposições que já foram tidas como verdadeira. Para mais, foi realizada a categorização dos dados por critério de relevância, postos em categorias de acordo com sua proximidade em relação ao tema, para que, dessa forma, sua análise possa exprimir significados relevantes que abranjam os objetivos do estudo. Por fim, foi feita a dedução e indução dos dados e a validação destes, por meio da análise com base em várias teorias (Campos \& Turato, 2009). Foi possível analisar os resultados em três categorias, a partir do objetivo do estudo: 1. Conjugalidade e mudanças trazidas pela doença 2. Coping focado no problema 3. Coping focado na emoção.

\section{Resultado e Discussão}

Os resultados e discussão foram divididos por categoria para facilitar sua apresentação. Cada categoria recebeu um subtítulo que indica o principal ponto a ser discutido e se inicia com falas dos participantes que ilustram tal temática. A problematização e indicação da literatura, bem como algumas outras falas, encontram-se também apresentadas.

\section{Conjugalidade e mudanças trazidas pela doença}

"Então ele era uma pessoa assim, bem passiva, muito amigo, tinha muito conhecido, muita gente gosta muito dele. Assim, a pessoa aceita sabe, que chega, sabe entrar

e sabe sair, graças a Deus. (...) Ele era chefe lá dentro, então a onde ele chegava, eles se agradavam dele, sabe? Assim, tinha muita aceitação, ele toda vida foi um homem assim bem honesto, bem direito sabe" (A.) 
"Então ela sempre foi muito dinâmica, e muita coisa eu devo a ela sabe? (...) "...eu vou me manter e me mantenho junto com ela, eu quero isso até o final, vou ficar junto, eu acho que eu sou muito importante pra ela sabe" (F.)

O casamento é integrante do acervo de relacionamentos interpessoais considerável para o desenvolvimento do bem-estar dos idosos, pois envolve elementos importantes da dimensão humana. Os relacionamentos são entendidos como duradouros e podem constituir um suporte para as situações estressoras quando satisfatórios (Campos et al., 2017). Ao analisar as falas sobre o relacionamento dos entrevistados antes do diagnóstico percebeu-se relações conjugais satisfatórias, o que pode ter sido um importante fator para que buscassem desenvolver estratégias para manter a conjugalidade, mesmo diante de um quadro de adoecimento. A admiração pelo parceiro surgiu como tema que sobressaiu durante a narrativa dos entrevistados. Estes trouxeram características positivas que observaram em seus parceiros durante os anos de casamento e que consideraram importantes para se manterem juntos.

A admiração pelo parceiro é uma estratégia que ajuda a regular os sentimentos negativos que podem surgir em decorrência do prolongado tempo de convivência e durante o processo da progressão da doença. Como aponta o estudo de Alves-Silva et al. (2017), realizado com casais em união estável há pelo menos 30 anos, um dos motivos que levam as pessoas a manterem um casamento de longa duração são as qualidades própria, do outro e construídas na relação. Nesta categoria, os casais relataram as características positivas em si e no parceiro que ajudam a manter a relação conjugal, dentre elas ressalta-se ser trabalhador, honesto, verdadeiro, carismático. Tais características positivas presentes no parceiro também surgem na narrativa dos entrevistados.

“(...) foi ela que me incentivou, eu, até então, eu ia ficar igual, na minha casa. Tinha o curso primário, era o suficiente na época, né? Ela que me estimulou, não se tem que estudar, eu estudei graças a ela, eu devo eternamente." (F.)
"Nós tinha uma serralheria, nós pois que aposentou né, ele aposentou por causa do ouvido, então nós fabricava. E nós trabalhava com salão de festa, eu e ele, essas peça assim ó, essas peça assim de ferro, tudo ele que fazia, né? Então, aquelas decoração forte de casamento tudo, a gente trabalhava com vários bufê lá de Uberlândia. Ele fazia as peça e eu pintava, né? Então era uma vida assim, que, que não tinha intriga." (A.)

A Psicologia Positiva reflete acerca da ligação entre o bem-estar pessoal e um relacionamento conjugal satisfatório. A relação pode servir para outras esferas da vida, além da pessoal, como, por exemplo, um suporte emocional para proporcionar o desenvolvimento individual (Campos et al., 2017). O incentivo a sonhos pessoais também é um dos fatores que contribui para a manutenção da boa conjugalidade.

É esperado que, em um casamento bem-sucedido, cada cônjuge detenha seus próprios projetos e desejos. Nota-se, no relato de F., que seu progresso profissional foi por ele atribuído principalmente ao estímulo de sua esposa. Ao relatar que, se não fosse por ela, permaneceria sem motivação para se especializar. F. aponta para a importância do relacionamento e como percebe no casamento uma fonte de apoio e incentivo a seu desenvolvimento pessoal. No caso de A., evidenciou-se também a percepção do casamento como fonte de suporte e busca de desenvolvimento, mas em um projeto coletivo. A. indica que o apoio e suporte no casamento foi mútuo para que se desenvolvessem e apoiassem na vida pessoal e profissional. No aspecto profissional, o casal atuou junto em uma mesma área, de forma colaborativa, o que contribuiu para a consolidação do vínculo do casal.

Além do apoio para o crescimento pessoal, Campos et al. (2017) expõem a importância dos casais se adaptarem a situações estressantes e adversas que se manifestam durante o casamento. Destacam, ainda, que o acúmulo dessas habilidades de adaptação proporciona a estabilidade da união. Situações que envolvem muitos casais, como organização financeira e criação de filhos se mostraram presentes nas falas dos entrevistados. 
“(...)graças a Deus a gente conseguiu criar os três [filhos], principalmente dar uma formação boa, né? Curso superior, odontologia, a duras penas. Não foi fácil, dando aula no estado, arrumando coisa outra pra fazer pra complementar, a dificuldade financeira vinha mesmo, e a gente foi vencendo, aí chegamos, aí, ué, com 54 anos juntos". ( $F$.)

"Casei nova, fui pra Goiânia, de Goiânia só pra São Paulo. Moramos em São Paulo mais de 20, acho que

25 anos, 30, em São Bernardo do Campo. E lá nós desenvolveu nossas vida e tivemo nossos filhos, né? $E$ depois a gente resolveu vir embora pra Uberlândia, né? Construimo nossa casa, né? Com muita força, porque se a gente tem força a gente consegue, né mesmo? Cê chega na cidade assim, cê não conhece ninguém, num tem nada, num tem dinheiro, num tem nada, mas ali cê fala, eu vou fazer a vida, você faz, você faz. E nós construimo a casa que nós morava". (A.)

Notou-se, nos relatos dos entrevistados, o quanto se mantiveram unidos a seus parceiros, apesar de todas as dificuldades que a vida impôs. A continuidade da união indica que conseguiram se adaptar e desenvolver estratégias de superação conjuntas para as demandas da vida e do cotidiano. Esses enfrentamentos estão presentes na vida de muitos casais e a forma como são contornados ajuda a explicar a forma como a conjugalidade se manifesta. Mas o surgimento de um diagnóstico crônico, como o do Alzheimer, representa um novo desafio para a conjugalidade dos casais (Garcia, 2018).

"Claro que houve uma mudança muito radical né? No comportamento, de mim pra ela, inclusive sexualmente né? A gente... já tem um tempo que eu não tenho relação, mais assim, eu não sinto falta não, sabe? Eu relevei. Falei, vou encarar isso aí como uma coisa que, se veio pra mim, é porque eu tenho os ombros largos pra aguentar né? Pra suportar. E, me dou bem com ela sabe, tranquilo. Trato ela com muito carinho, compreendendo que isso que ela tem, ela não tem culpa nenhuma, nem eu, nem ninguém." (F.)

“(...) explico, explico falo, não nós casô fez 50 ano agora em maio, né? E isso tudo. 'Não, mas eu acho que eu não sou casado, eu não sou casado não'. Falo é, ué, é casado sim. Aí ele fala pra mim 'eu não entendi não, eu não entendi não', aí eu vou falando com ele, aí ele guarda uns dois, três dias. Aí depois, aí, se eu não ficar falando, aí ele repete pra mim aquilo que ele não tem, né? Que ele não é casado, né?" (A.)
A análise das falas mostra que o surgimento de um diagnóstico como o Alzheimer altera o quadro de parceria na resolução das situações de dificuldade e gera mudanças na relação conjugal, principalmente no que se refere ao cônjuge com o diagnóstico e o agravamento de seus sintomas. A redução da atividade sexual é uma queixa frequente quando se analisa a vivência de casais de longa duração e pode ser agravada quando um dos parceiros tem Alzheimer (Sales \& Menezes, 2017).

Frente às mudanças demandadas os entrevistados desenvolveram formas de adaptação para amenizar o impacto negativo na relação e não haver afastamento do casal. Uma das formas adotadas passa pela reafirmação do vínculo, outra inclui a tentativa de rememoração de boas experiências como compensatórias para as mudanças negativas mais recentes. A. relata precisar lembrar o marido de que é casado com ela pelo menos a cada três dias. Isso demonstra a importância para ela de que, apesar do esquecimento, seu marido saiba que ela é sua mulher e que permanecem juntos. Enquanto F. relata as mudanças na sexualidade e a forma que tem enfrentado isso, focando na maneira como trata a esposa e buscando compreender que não há intenção ou culpa na mudança no relacionamento sexual do casal.

F. reitera que está decidido a manter-se ali, seja por razões afetivas que permanecem, como o comprometimento e a admiração, seja pela ansiedade, angústia e culpa que a separação pode gerar. Norgren et al. (2004) esclarecem acerca da possibilidade de casamentos também se manterem justamente por ambos abominarem a ideia de divórcio, medo da solidão, dificuldade de lidar com a liberdade, entre outras razões, e que estar casado passa a ser menos ansiogênico do que o divórcio.

As falas evidenciaram que as relações conjugais dos entrevistados eram satisfatórias antes do diagnóstico, ressaltando o apoio mútuo em situações delicadas da vida, o incentivo a suas metas profissionais e do carinho desenvolvido entre os parceiros. Norgren et al. (2004) trazem que as relações satisfatórias e duradouras permitem que a conjugalidade sirva de refúgio para situações estressoras. Frente a isso, pode-se pensar que a existência de uma boa relação prévia ao diagnóstico é um fator importante para que a conjugalidade se mantenha satisfatória durante um contexto hostil como o que o Alzheimer representa. 
Os entrevistados continuaram percebendo suas relações com os cônjuges como positiva, que passaram a buscar estratégias para se dedicarem ainda mais aos parceiros e estarem mais próximos. A participação no Movimente pode ser, inclusive, percebida como uma dessas medidas. Apesar disso, durante as entrevistas percebeu-se certa resistência por parte dos entrevistados em falar sobre a relação conjugal descontextualizada do diagnóstico. Os exemplos, os pontos de destaque espontâneos trazidos pelos entrevistados remetiam prioritariamente as mudanças após o surgimento do Alzheimer e as atividades demandadas para cuidar do cônjuge. Essa priorização pode indicar que o Alzheimer passou a ocupar um local de tema central em suas vidas, esmaecendo outras relações, mesmo a marital.

Apesar dessa observação, as falas permitiram identificar estratégias adotadas para manter uma conjugalidade satisfatória. Seguindo indicação da literatura para caracterização das estratégias de coping (Lazarus \& Folkman, 1991), as falas dos entrevistados foram sistematizadas quanto as estratégias adotadas, separadamente para o coping focado no problema e o focado nas emoções.

\section{Coping focado no problema}

“(...) quando ela vai no banho, por exemplo, a dificuldade que ela tem, ela, eu chego perto e não vem cá, eu vou te ajudar. To aqui firme, ai ela segura assim, eu sinto que ela sente segurança, sabe? De eu ta junto ali. Então isso aí da força pra continuar, ah, acompanhar tudo né, tem esse tempo aí, quanto tempo? Né, não sabe" (F.)

“(...) igual, as vezes de manhã nós dois sai, dá uma caminhada, isso pra mim é uma vitória, sabe? É uma vitória muito grande, dele ir, vim, comer. Eu ajudar ele no banho dele, organizar a roupa no corpo. A gente faz assim, não porque, ah coitadinha, não. A gente faz porque é o verdadeiro amor..." (A.)

Para Folkman e Lazarus (1980), o coping focalizado no problema consiste em um esforço atuante para tentar modificar a situação estressora. Ao adotar estratégias focadas no problema os casais buscam alterar a forma como agem, reduzindo, com isso, conflitos e situações consideradas problemáticas (Mussumeci \& Ponciano, 2018).

As falas dos entrevistados permitiram notar que o comprometimento foi a estratégia de coping mais adotada e se manifestou como comportamentos objetivos de cuidado prestados ao cônjuge com Alzheimer. Quando questionados sobre o que mudou na relação conjugal após o diagnóstico, ambos os entrevistados indicaram que houve mudanças e que consideravam importante estar próximos de seus parceiros no dia a dia, cuidando e ajudando nas pequenas coisas, citando as caminhadas, preparação de alimentos, realização de compras para o domicílio ou auxiliar no banho como formas de manifestar seu comprometimento. Esse padrão de comportamento, de remodelar hábitos do cotidiano para assumir atividades de cuidado no cotidiano já havia sido identificado por Souza et al. (2016) ao investigar cônjuges de pessoas com quadro demencial.

Silva et al. (2017) trazem quatro categorias significativas sobre estratégias para manutenção de casamentos de longa duração, dentre elas a categoria doação e o comprometimento, a qual refere-se a uma necessidade de comprometimento e doação do parceiro ou parceira em relação ao casamento. Destacam que, em meio à rotina e tudo o que a vida estabelece, faz-se essencial, dentro de uma relação, a abdicação, doação e comprometimento para um casamento duradouro e que tais características precisam estar presentes constantemente. Além disso, pontuam que os casamentos de longa duração são vistos com seriedade em relação aos casamentos contemporâneos, em que o primeiro preza o casamento "até que a morte nos separe" e o segundo demonstra mais flexibilidade caso não dê certo.

"...eu era um sonhador e, ah, umas loucura que a gente fazia e ela segurou o tranco né? O tempo todo, renegou muita coisa, se fosse uma outra pessoa que não tivesse a, o pulso que ela teve, né, de manter um casamento. Vo falá pra você que não teria tido, acabado o casamento próximo algumas vezes, mais por culpa minha, não dela, sabe? Eu carrego esse, esse ônus até hoje e vou carregar pra sempre, ela já segurou muita barra, sabe?" (F.) 
O comprometimento em um casamento de longa duração também pode surgir como uma forma de reparação. No estudo feito por Melo (2009), com cônjuges homens que eram cuidadores de suas parceiras, notou-se que, no percurso conjugal destes, alguns cuidadores tinham a necessidade de se dedicar a suas parceiras como forma de amenizar o sofrimento que haviam causado previamente durante o casamento. Por não terem tido o comportamento conjugal esperado anteriormente, buscavam uma forma de compensação, que se manifestava em atitudes concretas no cotidiano para manter o bom relacionamento conjugal. Algumas falas de F. indicaram um comportamento nesse sentido, em que suas ações para permanecer presente, relevar perdas sexuais ou de manifestações afetivas por parte da esposa e ainda ocupar o lugar de cuidador e provedor são entendidas como pagamento pelo investimento prévio da esposa em momentos prévios do relacionamento.

Segundo a definição de Lazarus e Folkman (1991), o coping focado no problema representa uma estratégia efetiva para minimizar o impacto negativo de situações percebidas como negativas. Sua adoção aumenta a sensação de controle ambiental e contribui ativamente para a manutenção das emoções positivas. Assim, a adoção de estratégias de coping focadas no problema podem contribuir ativamente para a manutenção da satisfação conjugal.

\section{Coping focado na emoção}

“...eu creio que Deus tenha assim um propósito pra cada um de nós que tamo aqui, então a gente tem que passar por determinadas situações que eu não posso transferir pra ninguém, porque é minha. Então eu tenho que ir até a hora que Deus determinar. Então eu levo meu dia assim, sabe, buscando força, assim não tem com quem eu converso, então eu busco força em

Deus." (A.)

"Isso talvez tenha me ajudado a enfrentar. Quem sabe né? Eu ter essa vontade de continuar, de fazer o melhor de mim pra situação que eu convivo hoje, né? Acho que é importante a pessoa que já teve alguma experiência, é, dessa, dessa, doar né? De doação, a gente aprende muita coisa nesses lugares viu. Parece que não, mas a gente só vai dar valor depois, tem muito exemplo lá, de pessoas que superaram, né, crises difíceis. Então acho que ta me servindo também de alicerce, do que eu to passando hoje, né? Acho que religião hoje é muito importante né? Qualquer que seja" (F.)
Para Folkman e Lazarus (1980), o coping focalizado na emoção é o esforço emocional para regular o evento estressante, portanto tem como propósito modificar o estado emocional do indivíduo. O coping focalizado na emoção não atua na tentativa de alterar a situação estressora, mas em minimizar o sofrimento com que o indivíduo irá lidar com dela.

Entre as estratégias de coping adotadas por casais, e por cuidadores de pessoas com condições crônicas, as crenças religiosas assumem um papel de destaque (Pargament et al., 1988). O coping religioso/espiritual pode ser focalizado tanto na emoção quanto no problema, podendo gerar resultados tanto positivos quanto negativos. Estratégias com efeito positivo seriam a busca pelo conforto e resolver os problemas se apoiando em Deus. Enquanto estratégias com efeito negativo seriam questionar a existência, sentir descontentamento em relação a Deus e ver o estressor como punição divina (Panzini \& Bandeira, 2007).

O aspecto positivo das crenças religiosas se destacou na fala dos entrevistados. Portanto, a religiosidade/espiritualidade mostrou-se como uma estratégia de coping, em que os entrevistados puderam se apoiar para enfrentar o estressor Alzheimer e, dessa forma, não culpabilizar seus parceiros. Nota-se nas falas dos entrevistados que o coping religioso/espiritual teve efeito positivo para eles, pois A. busca força em Deus para enfrentar seus dias. Como não dispõe de uma rede de apoio que auxilie concretamente, a crença religiosa ganha importância em seu bem-estar. Enquanto F. utiliza-se desta crença para entender que ninguém tem culpa pela situação que precisa manejar e considerar-se forte o suficiente para encarar esse estressor, por crer que não receberia uma situação para resolver com a qual não conseguiria lidar.

Quando foram questionados sobre como se sentiram após receber o diagnóstico de seu cônjuge, ambos os entrevistados demonstraram acreditar que o Alzheimer veio como uma "provação" pela qual precisavam passar. A. foi explícita em sua crença em Deus e em uma religião específica, demonstrando em sua fala a aceitação do que foi imposto por Deus e que toma essa crença como fonte de força. Enquanto $F$ não cita Deus ou qualquer religião diretamente ao longo da entrevista, entretanto, refere-se ao diagnóstico de sua esposa como uma missão enviada a ele. 
A partir desta fala, F. foi questionado sobre sua religião, e relatou a importância da religião para o enfrentamento da situação que vivencia.

Panzini e Bandeira (2007) utilizam o termo coping religioso/espiritual para se referir ao uso da religião, espiritualidade ou fé para lidar com situações de estresse ou negativas que ocorrem ao longo da vida. Silva et at. (2017) evidenciam a categoria "espiritualidade" como forma de manter o casamento duradouro, trazendo-a como um elemento de apoio ou mesmo de fuga para enfrentar situações de conflito. Apontando, inclusive, a espiritualidade como forma de esperança de que as coisas podem melhorar.

Pargament et al. (1988) realizaram um estudo com membros de uma igreja Presbiteriana e Luterana do Missouri e perceberam três estilos de resolução de problemas focalizados na religião: autodireção, delegação e colaboração. Autodireção diria respeito ao indivíduo ser ativo e Deus passivo na resolução dos problemas. delegação, em que o indivíduo é passivo e espera que Deus solucione seus problemas; e colaboração, quando ambos são ativos e responsáveis na resolução dos problemas. Posteriormente, Panzini e Bandeira (2007) acrescentaram dois outros estilos, a súplica, em que o indivíduo é ativo na influência da vontade divina, suplicando repetidas vezes por sua intervenção e a renúncia, em que o indivíduo renuncia a seus desejos para acatar à vontade de Deus. Nesse caso, ambos são ativos na resolução do problema, entretanto, há uma submissão por escolha própria da vontade do indivíduo à vontade de Deus, o que difere da delegação.

A renúncia pode ser percebida nas falas dos entrevistados, quando ambos se mostram conformados acerca da doença de seus parceiros e deixam à mercê da vontade de Deus a resolução da situação. A adoção dessa estratégia não modifica a situação concreta, mas pode auxiliar a manter um senso de proteção e sentir sua situação de forma mais leve. Assim, essa estratégia pode representar uma forma de enfrentamento que pode amenizar a desestabilização da relação conjugal.
Folkman (1984) fala da importância do coping focado na emoção por ser uma estratégia que dará o suporte necessário para o êxito dos esforços focados no problema. Ao considerar que diversas emoções intensas abalam as atividades cognitivas para focar no problema, adotar formas de pensar que permitam manter a tranquilidade, sentir-se acolhido em algum nível, pode contribuir para o bem-estar (Pinto \& Barham, 2014). Quando o enfrentamento é bem-sucedido pode ajudar não somente na resolução de problemas e no gerenciamento das emoções, mas também na proteção das relações interpessoais durante momentos estressores, trazendo maior satisfação ao indivíduo.

O presente trabalho apresenta pontos positivos ao investigar aspectos da relação de cônjuges de pessoas com quadros neuropsiquiátricos pouco investigados até o presente momento, sua conjugalidade e as estratégias que adotam para mantê-la. Além disso, a adoção de entrevistas permitiu que os participantes se sentissem mais livres para dizer sobre suas experiências e indicar os pontos que gostariam de destacar. Mas o trabalho tem algumas limitações que precisam ser indicadas. Apenas um dos cônjuges de cada casal foi entrevistado, portanto não sabemos se as estratégias adotadas pelo outro integrante do casal e suas percepções são coincidentes. Além disso, o estudo limitou suas comparações devido à escassez na literatura sobre casamentos de longa duração quando um dos cônjuges possui algum transtorno neuropsiquiátrico. Outra limitação que precisa ser destacada foi a dificuldade para encontrar cônjuges para a pesquisa. Estes dificilmente frequentam os grupos de apoio, lugar no qual poderiam interagir com outras pessoas e exercer o coping focalizado no relacionamento, indicado por O'Brien e DeLongis (1996) como importante estratégia de enfrentamento para gerenciar e manter relacionamentos durante períodos estressantes.

Como o tema abordado no presente trabalho é ainda pouco investigado, estudos futuros ganham maior importância. Investigações com cônjuges que não estejam vinculados a programas de intervenção com idosos e que adotem formas diferentes para avaliar o coping e a conjugalidade dos casais podem ser formas de compreender melhor esses conceitos. 


\section{Conclusão}

Os resultados deste estudo possibilitaram analisar quais as estratégias de coping utilizadas por dois cônjuges de idosos com Alzheimer para manter a conjugalidade e os impactos que a doença impõe na relação conjugal. Os participantes demonstraram utilizar tanto coping focalizado na emoção quanto no problema. E, dentro desses dois tipos, foi possível identificar as principais estratégias utilizadas, sendo o comprometimento e crença religiosa as mais significativas.

Embora os estudos sobre casamentos de longa duração geralmente abordem ambos os cônjuges que compõe o casal, foi possível comparar os achados do presente trabalho com algumas estratégias individuais utilizadas por outros casais. As estratégias analisadas se mostraram eficazes em seu objetivo de manter a conjugalidade, pois notou-se que ambos os entrevistados, apesar de todo sofrimento e dificuldades que o Alzheimer provoca, mantêm-se ligados afetivamente a seus parceiros. Ademais, pôde-se perceber durante as entrevistas o cuidado que os participantes tinham com os parceiros e o quanto esse cuidado e companheirismo em um contexto de adoecimento é relevante para saúde do idoso diagnosticado.

Com este estudo espera-se contribuir para mais produções científicas sobre estratégias mantenedoras de casamentos duradouros quando há a presença de transtornos neuropsiquiátricos em um dos cônjuges. Além disso, com a compreensão das estratégias de enfrentamento pode-se desenvolver intervenções psicológicas que auxiliem e dê apoio para o indivíduo como cuidador e como cônjuge, visando manter a relação com seu parceiro saudável apesar de todas as limitações que uma doença neuropsiquiátrica provoca.

\section{Contribuições das autoras}

Comelli G idealizou o projeto, coletou os dados, realizou a análise de dados e redação do artigo. Barroso SM idealizou o projeto, colaborou na análise dos dados e revisão do artigo para publicação.

\section{Conflitos de interesses}

Nenhum conflito financeiro, legal ou político envolvendo terceiros (governo, empresas e fundações privadas, etc.) foi declarado para nenhum aspecto do trabalho submetido (incluindo, mas não se limitando a subvenções e financiamentos, participação em conselho consultivo, desenho de estudo, preparação de manuscrito, análise estatística, etc.).

\section{Referências}

Alves-Silva, J. D., Scorsolini-Comin, F., \& Santos, M. A. (2017). Bodas para uma Vida: Motivos para Manter um Casamento de Longa Duração. Temas em Psicologia, 25(2), 487-501. http:// dx.doi.org/10.9788/TP2017.2-05

American Psychiatric Association. (2014). Manual diagnóstico e estatístico de transtornos mentais (DSM-5) (5a ed., M. I. C. Nascimento, P. H. Machado, R. M. Garcez, R. Pizzato, \& S. M. M. Rosa, Trads.). Artmed.

Campos, C. J. G., \& Turato, E. R. (2009). Análise de conteúdo em pesquisas que utilizam metodologia clínico-qualitativa: Aplicação e perspectivas. Revista Latino Americana Enfermagem, 17(2). https://doi.org/10.1590/S010411692009000200019

Campos, S. O., Scorsolini-Comin, F., \& Santos, M. A. (2017). Transformações da conjugalidade em casamentos de longa duração. Psicologia Clinica, 29(1), 69-89. http://pepsic.bvsalud.org/scielo.php?script=sci_ arttext\&pid=S0103-56652017000100006\&lng=pt\&t|ng=pt

Mattos, E. B. T., \& Kovács, M. J. (2020). Doença de Alzheimer: a experiência única de cuidadores familiares. Psicologia USP, 31, e180023. https://doi.org/10.1590/0103-6564e180023 
Folkman, S., \& Lazarus, R. S. (1980). An analysis of coping in a middle-aged community sample. Journal of Health and Social Behavior, 21(3), 219-239. https://doi. org/10.2307/2136617

Folkman, S. (1984). Personal control and stress and coping processes: a theorical analysis. Journal of Personality and Social Psychology, 46(4), 839-852. https://doi. org/10.1037/0022-3514.46.4.839

Garcia, C. R. (2018). Conjugalidade, funcionamento familiar e doença de Alzheimer: um estudo com cuidadoras esposas brasileiras e portuguesas [Dissertação de Mestrado, Universidade de São Paulo]. Biblioteca digital USP. http:// doi.org/10.11606/D.100.2018.tde-02072018-091424

Lazarus, R. S., \& Folkman, S. (1991). The concept of coping. In A. Monart, \& R.S. Lazarus (Eds), Stress and coping: an anthology (3a. ed., pp.127-148). Columbia University Press.

Melo, G. (2009). A experiência vivida de homens (cônjuges) que cuidam de mulheres com demência. Revista Brasileira de Geriatria e Gerontologia, 12(3), 319-330. https://doi. org/10.1590/1809-9823.2009.00002

Mosmann, C. P., \& Wagner, A. (2006). Qualidade conjugal: mapeando conceitos. Paidéia (Ribeirão Preto), 16(35), 315325. https://doi.org/10.1590/S0103-863X2006000300003

Mussumeci, A. A., \& Ponciano, E. L. T. (2018). Coping e Coping Diádico: Uma Análise Qualitativa das Estratégias de Coping de Casais. Psicologia Clinica, 30(1), 165-190. http://pepsic. bvsalud.org/scielo.php?script=sci_abstract\&pid=\$0103$\underline{56652018000100010 \& \operatorname{lng}=p t \& n r m=i s o}$

Norgren, M. B. P., Souza, R. M., Kaslow, F., Hammerschmidt, H., \& Sharlin, S. A. (2004). Satisfação conjugal em casamentos de longa duração: uma construção possível. Estudos de Psicologia (Natal), 9(3), 575-584. https://doi.org/10.1590/ $\underline{\mathrm{S} 1413-294 \times 2004000300020}$

O'Brien, T. B., \& DeLongis, A. (1996). The interactional context of problem-, emotion-, and relationship-focused coping: The role of the big five personality factors. Journal of Personality, 64(4), 775-813. http://doi. org/10.1111/j.1467-6494.1996.tb00944.x

Panzini, R. G., \& Bandeira, D. R. (2007). Coping (Enfrentamento) religioso/espiritual. Revista Psicologia Clínica, 34(1), 126135. https://doi.org/10.1590/S0101-60832007000700016
Pargament, K. I., Kennell, J., Hathaway, W., Grevengoed, N., Newman, J., \& Jones, W. (1988). Religion and the problemsolving process: three styles of coping. Journal for the Scientific Study of Religion, 27(1), 94-104. https://doi. org/10.2307/1387404

Pinto, F. N. F. R., \& Barham, E. J. (2014). Bem estar psicológico: Comparação entre cuidadores de idosos com e sem demência. Psicologia, Saúde \& Doenças, 15(3), 635655. https://dx.doi.org/10.15309/14psd150307

Prince, M., Comas-Herrera, A., Knapp, M., Guerchet, M., \& Karagiannidou, M. (2016). World Alzheimer Report 2016: improving health care for people living with dementia. Alzheimer's Disease International. https://www.alzint. org/u/WorldAlzheimerReport2016.pdf

Sales, M. G. S., \& Menezes, T. M. O. (2017). Significado da sexualidade para o cônjuge cuidador de pessoa idosa com doença de Alzheimer. Revista Rene, 18(2), 204-211. http:// doi.org/10.15253/2175-6783.2017000200009

Silva L. G., Campos T. G., Sousa J. P., Lemos I. C. S., Fernandes G. P., \& Kerntopf M. R. (2015). Aspectos Emocionais Vivenciados Por Familiares Frente à Responsabilidade do Cuidado ao Idoso com Alzheimer. Uniciências, 19(2), 102-105. https://revista.pgsskroton.com/index.php/ uniciencias/article/view/3586/3117\#: : :text=Quando\%20 se $\% 20$ trata\%20de\%20doen\%C3\%A7a,aliviar\%200\%20 sofrimento\%20do\%20doente

Silva, L. A., Scorsolini-Comin, F., \& Santos, M. A. (2017). Casamentos de Longa Duração: Recursos Pessoais como Estratégias de Manutenção do Laço Conjugal. Psico-USF, 22(2), 323-335. https://doi.org/10.1590/141382712017220211

Souza, T. E. C., Souza, I. P., Araújo, L. F. S., Bellato, R., \& Soares, J. L. (2016). Potenciais educativos na situação crônica do Alzheimer: Cenas do Cuidado pelo Homem-Esposo. Revista Mineira de Enfermagem, 20, e946. http://www.reme.org.br/ artigo/detalhes/1093

Viero, G. M., \& Santos, C. G. (2019). O Alzheimer como um desafio aos sistemas de saúde, frente a crescente expectativa de vida, e o MEEM como ferramenta no rastreio de demências. Brazilian Journal of Health Review, 2(3), 15451554. https://www.brazilianjournals.com/index.php/BJHR/ article/view/1387/1533

Yin, R. K. (2015). Estudo de caso: Planejamento e Métodos. Bookman. 